\title{
Quadricuspid aortic valve surgical repair
}

Rebeca Lorca, MD, ${ }^{\mathrm{a}}$ Rubén Álvarez-Cabo, $\mathrm{MD},{ }^{\mathrm{b}}$ Juan Calvo, $\mathrm{MD}, \mathrm{PhD},{ }^{\mathrm{c}}$ and Jesús María de la Hera, MD, $\mathrm{PhD}^{\mathrm{a}}$

From the Departments of ${ }^{\mathrm{a}}$ Cardiology, ${ }^{\mathrm{b}}$ Cardiovascular Surgery, and ${ }^{\mathrm{c}}$ Radiology, Hospital Universitario Central de Asturias, Oviedo, Spain.

Disclosures: Authors have nothing to disclose with regard to commercial support.

Received for publication Aug 15, 2017; revisions received Oct 23, 2017; accepted for publication Nov 7, 2017; available ahead of print Dec 6, 2017.

Address for reprints: Rebeca Lorca, MD, Department of Cardiology, Hospital Universitario Central de Asturias, Av Roma, s/n, 33011 Oviedo, Asturias, Spain (E-mail: lorcarebeca@ gmail.com).

J Thorac Cardiovasc Surg 2018;155:940-1

$0022-5223 / \$ 36.00$

Copyright (C) 2017 by The American Association for Thoracic Surgery

https://doi.org/10.1016/j.jtcvs.2017.11.008

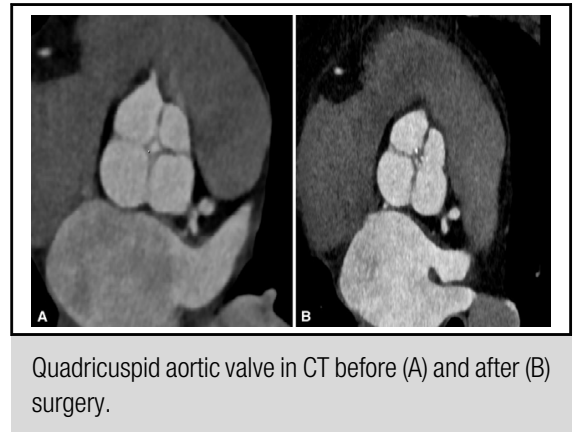

Central Message

We report the case of young patient with a quadricuspid aortic valve, an extremely infrequent congenital valve disease, which was successfully repaired, avoiding the implications of valve replacement.

See Editorial Commentary page 942.

Quadricuspid aortic valve (QAV) is a rare cardiac condition, with an incidence from $0.008 \%$ to $1.46 \%$, depending on the series consulted. Unfortunately, both mechanical and biologic valve replacements present prosthesis-related complications (thromboembolism, valve thrombosis, and hemorrhages related to the mandatory anticoagulation ${ }^{1}$ in mechanical valves, or valve degeneration in the biologic ones). Although there have been no randomized studies to compare aortic valve repair with replacement, some studies suggest that valve repair may reduce the risk of prosthesis-

related complications. ${ }^{2}$ As a result, surgical valve repair may be considered the first therapeutic option in young patients with QAV and severe aortic regurgitation.

We present the case of a 50-year-old man with a diagnosis of QAV and severe aortic regurgitation (Figure 1, A). He was
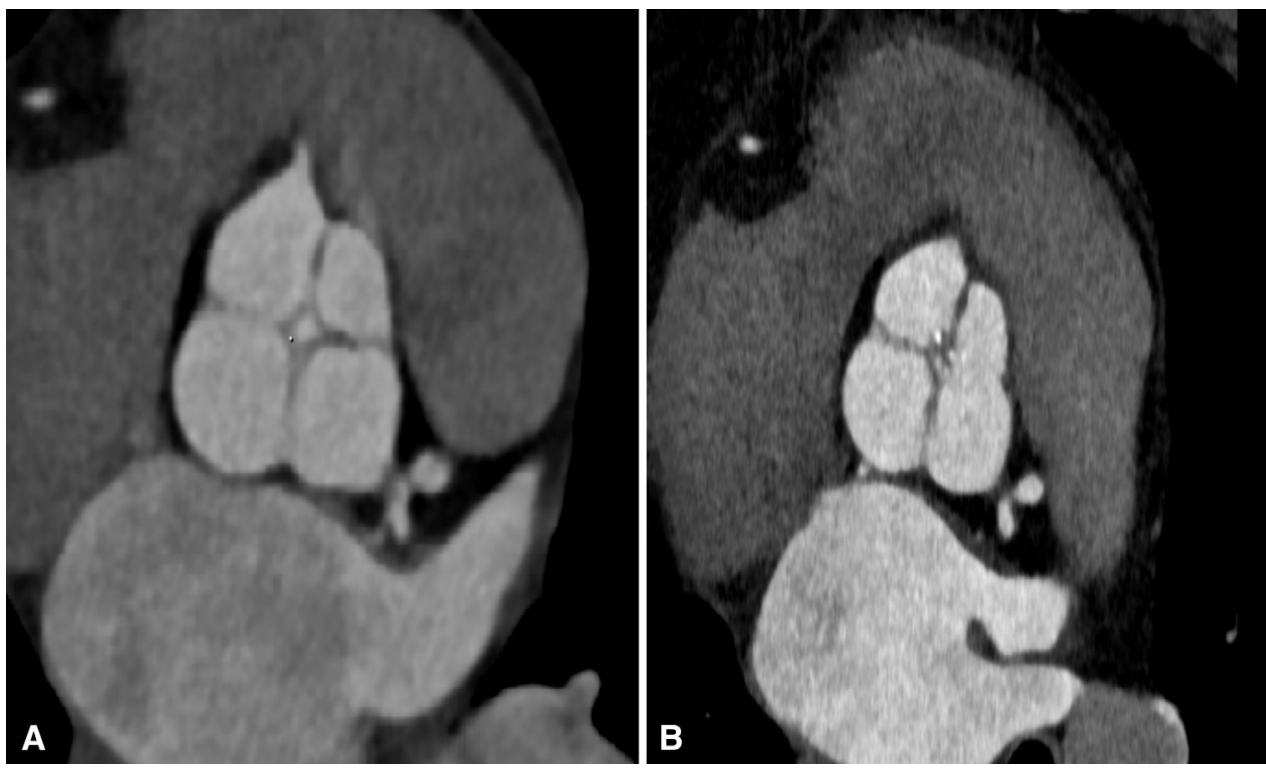

FIGURE 1. A, Quadricuspid aortic valve visualized with cardiac computed tomography. B, Quadricuspid aortic valve converted into a tricuspid aortic valve and visualized with cardiac computed tomography. 


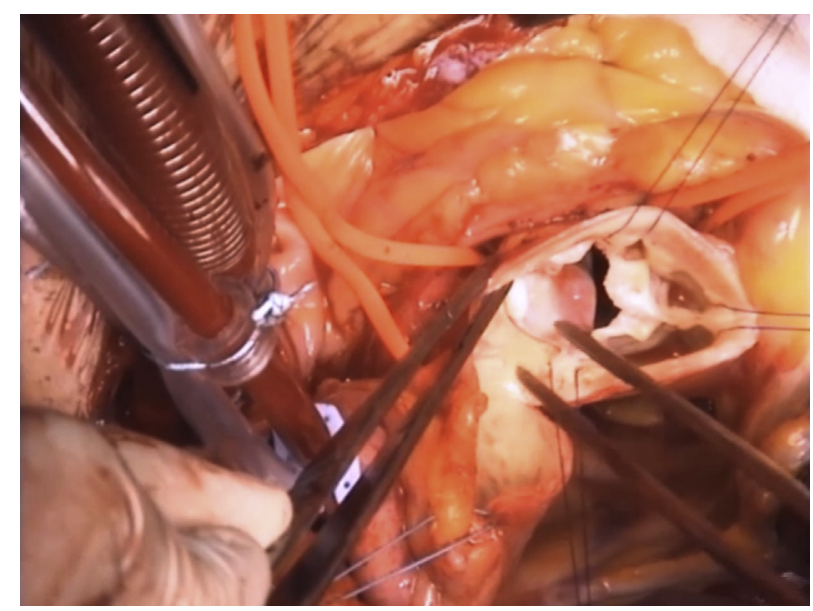

VIDEO 1. Surgical procedure, plus imaging before and after the procedure. Video available at: http://www.jtcvsonline.org/article/S00225223(17)32507-2/fulltext.

referred to surgery and consented to undergo aortic valve repair (Figure 1, B). The surgical procedure started with transverse aortotomy and examination of aortic leaflets, followed by annuloplasty with suture of the aortic annulus. ${ }^{3}$
Afterward, the QAV was converted into a tricuspid valve through fenestration sectioning, edge shaving, and left and accessory leaflet suturing. Leaflet central placation ${ }^{4}$ was then performed. Finally, an annuloplasty with suture of the sinotubular junction was performed (Video 1). The conversion into a tricuspid valve, together with aortic valve repair techniques, allowed the correction of the insufficiency and enabled achievement of a good effective height and coaptation of the aortic leaflets, essential for durability of repair. The patient was discharged with a functional converted tricuspid aortic valve and only mild aortic regurgitation.

\section{References}

1. Hammermeister K, Sethi GK, Henderson WG, Grover FL, Oprian C, Rahimtoola SH. Outcomes 15 years after valve replacement with a mechanical versus a bioprosthetic valve: final report of the Veterans Affairs randomized trial. J Am Coll Cardiol. 2000;36:1152-8.

2. Aicher D, Fries R, Rodionycheva S, Schmidt K, Langer F, Schäfers HJ. Aortic valve repair leads to a low incidence of valve-related complications. Eur J Cardiothorac Surg. 2010;37:127-32.

3. Aicher D, Schneider U, Schmied W, Kunihara T, Tochii M, Schäfers HJ. Early results with annular support in reconstruction of the bicuspid aortic valve. J Thorac Cardiovasc Surg. 2013;145(3 Suppl):S30-4.

4. Aicher D, Langer F, Adam O, Tscholl D, Lausberg H, Schäfers HJ. Cusp repair in aortic valve reconstruction: does the technique affect stability? J Thorac Cardiovasc Surg. 2007;134:1533-8; discussion 1538-9. 